Original

\title{
Ion channels in in situ rod of the frog retina as revealed by intracellular current injection
}

\author{
Kyoh-Ichi Takahashi \\ Department of Physiology, School of Medicine, Keio University \\ 35 Shinanomachi, Shinjuku-ku, Tokyo 160, Japan
}

(Received for publication on June 12, 1986)

\begin{abstract}
In order to reveal the characteristics of ion channels, the in situ rods of the frog retina were stimulated by intracellular current injection. Transient depolarizations were observed not only at the onset of the application of the depolarizing current, but also at the termination of the hyperpolarizing current. Experiments in perfusate containing ion channel blockers, $\mathrm{Co}^{2+}$ and TEA, revealed that the both depolarizations were attributed to the activation of the voltage-dependent $\mathrm{Ca}^{2+}$ current, and appeared transient being counteracted by hyperpolarization due to the voltage-dependent or the $\mathrm{Ca}^{2+}$-dependent $\mathrm{K}^{+}$current. In addition, $\mathrm{Cs}^{+}$application eliminated a negative transient response produced at the onset of the hyperpolarizing current, suggesting that it was attributed to the $h$ current. All the ion channels observed in in situ frog rods were identical to those found in enzymatically isolated sa!amander rods, indicating that the cell dissociation procedures did not affect the rod membrane properties. In addition, taking into account the direction of the stimulus current and the rectification of the rod cell membrane, the active site for producing the $\mathrm{Ca}^{2+}$ response was not restricted solely to the rod terminal, but the inner segment also could produce $\mathrm{Ca}^{2+}$ response.
\end{abstract}

Key words: frog retina, rod, $\mathrm{Ca}^{2+}$ channel, $\mathrm{K}^{+}$channel, ion channel blockers

\section{Introduction}

In rods of the vertebrate retina, spontaneous generation of a $\mathrm{Ca}^{2+}$ response was frequently observed when the retina was perfused with solutions which contained some 
of ion channel blockers. ${ }^{1}$ Recently Miyachi et al. $^{2}$ observed that, even in Ringer solution containing none of blockers, the frog rod produced the $\mathrm{Ca}^{2+}$ response when the retina was electrically stimulated by transretinal current pulses to depolarize the rod terminal, where the $\mathrm{Ca}^{2+}$ channel is believed to operate in releasing the neurotransmitter.

A detailed analysis of ion channels has been carried out using enzymatically isolated salamander rods which frequently lost their outer segments and/or terminals during dissociation procedures, ${ }^{3,4}$ Even in the 'solitary inner segments', several ionic currents were separately recorded including the voltage-dependent $\mathrm{Ca}^{2+}$ current. ${ }^{2}$ Therefore, the first purpose of the present experiment is to re-examine the site of $\mathrm{Ca}^{2+}$ channel activation in in situ rods. The in situ rods of the frog retina were electrically stimulated by intracellular current injections with various current intensities and durations of either polarity, and the evoked responses were analyzed by application of several ion channel blockers. The results showed that the active site for generating the $\mathrm{Ca}^{2+}$ response is not restricted solely at the rod terminal, but the response was generated at the inner segment as well.

Since the isolated salamander rods were prepared through many steps of the enzymatic and mechanical cell dissociations and the subsequent primary culture, ${ }^{3,4}$ another aim of this experiment is to examine whether ion channels in the isolated rods are preserved intact as those in in situ rods. Experiments similar in purpose have sporadically appeared, ${ }^{1,5-7}$ but no thorough experiment has yet been carried out. Though the present experiment on the in situ frog rods inevitably lacked quantitative precision, the results showed that the ion channels are qualitatively identical irrespective of animal species and rod preparations, either isolated or in situ.

\section{Material and Methods}

Material and perfusion: Experiments were performed on in situ rods in the retina of the bullfrog, Rana catesbeiana. After dark-adaption, the animals were decapitated and the eyes were enucleated. The retina was detached and was placed with the receptor side up on a piece of filter paper. The preparation was mounted in a perfusion chamber (capacity: $0.7 \mathrm{ml}$ ), and was continuously perfused (flow rate: $1 \mathrm{ml} / \mathrm{min}$ ) with various solutions whose compositions are described in Table 1 . The temperature of the solutions was regulated at $20 \pm 2^{\circ} \mathrm{C}$.

Transretinal and intracellular current applications and potential recordings: Details of transretinal current application have been described elsewhere.2 However briefly, current pulses were applied between two current electrodes; one was an $\mathrm{Ag}-\mathrm{AgCl}$ wire ring placed in a perfusate above the retina and the other was a grounded $\mathrm{Ag}-\mathrm{AgCl}$ plate placed on the bottom of the perfusion chamber. Intracellular microelectrodes were filled with $4 \mathrm{M}$ potassium acetate solution (resistance: 80-120 M $\Omega$ ). Responses were fed to a preamplifier equipped with an active bridge circuit (MEZ 8201, Nihon Kohden) and 
Table 1

Composition of the perfusing solutions (in $m M$ )

\begin{tabular}{|c|c|c|c|c|c|c|c|c|c|c|}
\hline Soln & $\mathrm{NaCl}$ & $\mathrm{KCl}$ & $\mathrm{MgCl}_{2}$ & $\mathrm{CaCl}$ & $\mathrm{CoCl}_{2}$ & TEA-Cl & $\mathrm{CsCl}$ & Choline- $\mathrm{Cl}$ & Glucose & *HEPES \\
\hline A & 106.0 & 2.5 & 0.8 & 1.8 & $\ldots$ & $\ldots$ & $\ldots$ & $\ldots$ & 5.6 & 3.0 \\
\hline B & 106.0 & 2.5 & 0.8 & 1.8 & 3.0 & $\ldots$ & $\ldots$ & $\ldots$ & 5.6 & 3.0 \\
\hline C & 86.0 & 2.5 & 0.8 & 1.8 & $\ldots$ & 20.0 & $\ldots$ & $\ldots$. & 5.6 & 3.0 \\
\hline$C^{\prime}$ & 86.0 & 2.5 & 0.8 & 1.8 & $\ldots$ & $\ldots$ & $\ldots$ & 20.0 & 5.6 & 3.0 \\
\hline $\mathbf{D}$ & 86.0 & 2.5 & 0.8 & 1.8 & 3.0 & 20.0 & $\ldots$. & $\ldots$. & 5.6 & 3.0 \\
\hline $\mathbf{E}$ & 96.0 & 2.5 & 0.8 & 1.8 & $\ldots$ & $\cdots$ & 10.0 & $\ldots$ & 5.6 & 3.0 \\
\hline $\mathbf{E}^{\prime}$ & 96.0 & 2.5 & 0.8 & 1.8 & $\ldots$. & $\ldots$ & $\ldots$. & 10.0 & 5.6 & 3.0 \\
\hline
\end{tabular}

1) In all solutions, the $\mathrm{pH}$ was adjusted to 7.8 with $\mathrm{NaOH}$.

2) *HEPES: N-2-hydroxyethylpiperazine-N'-2-ethanesulphonic acid.

3) In Solns $\mathrm{B}$ and $\mathrm{D}, 3.0 \mathrm{mM} \mathrm{CoCl}$, was added without molarity compensation.

4) Solns $C^{\prime}$ and $E^{\prime}$ were used as control solutions for Solns $C$ and E, respectively (see the text).

displayed on an oscilloscope (VC10, Nihon Kohden).

Light stimulation: The retina was diffusely illuminated with a monochromatic light of $500 \mathrm{~nm}$ which corresponded to the absorption maximum of the frog rhodopsin. The duration was $500 \mathrm{msec}$, and the intensity $\left(8.2 \times 10^{3}\right.$ photons $\left.\cdot \mu \mathrm{m}^{-2} \cdot \mathrm{sec}^{-1}\right)$ was below the threshold of cones.

Cell identification: Intracellular stainings were made with Lucifer Yellow $\mathrm{CH}$ (Aldrich Chemical Co.) in several initial experiments. Thereafter, penetrated cells were unequivocally identified as rods by their recorded depths, shapes and time courses of the light responses, and the spectral response maximum at $500 \mathrm{~nm}$.

\section{Results}

Stimulus current polarity and rod response

In the rod of the retina perfused with frog's normal Ringer solution (Soln $A$ in Table 1), a transretinal current pulse, flowing from the receptor side to the vitreous side, evoked a transient depolarization frequently followed by an oscillation." Fig. 1A shows such responses to brief current pulses $(5 \mathrm{msec}, 10 \mathrm{~mA})$ which were given at different timings during the light responses. The response showed the damped oscillation with a frequency of about $2 \mathrm{~Hz}$, being comparable to that observed by other investigators. ${ }^{1.8}$ Miyachi et al."2 have observed that the amplitude of the evoked response varied with $\mathrm{Ca}^{2+}$ concentration in the perfusate, and was enhanced by perfusion with $\mathrm{Ba}^{2}+$ containing soiution, while suppressed by exposure to $\mathrm{Co}^{*+}$. Taking into account the current direction, they pre.iminarily concluded that the electrically evoked depolariza- 

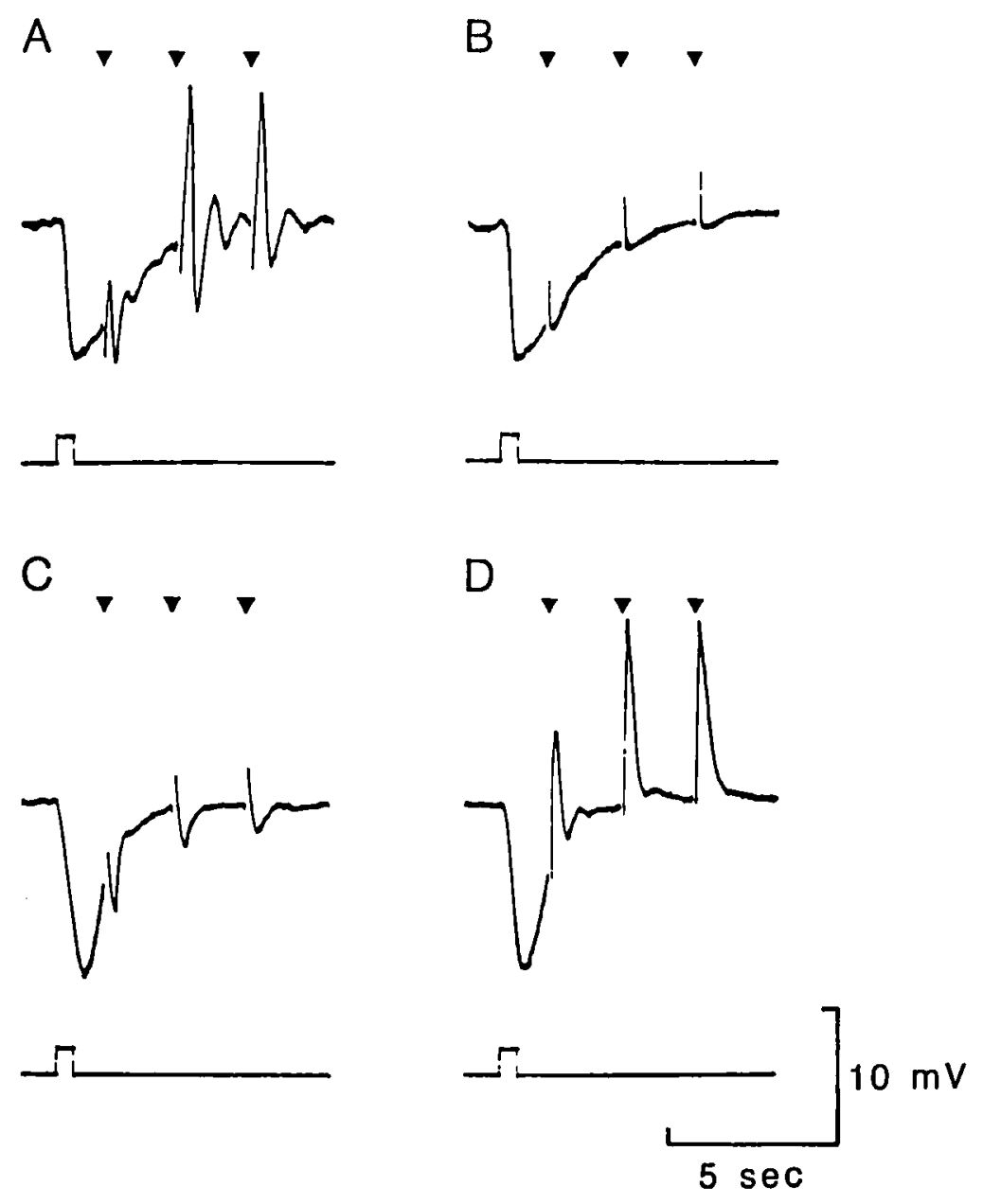

Fig. 1 Rod responses to electrical stimulations. A: Responses evoked by transretinal current flowing from the receptor side to the vitreous side (intensity: $10 \mathrm{~mA}$, duration: $5 \mathrm{msec}$ ). B: Transretinal current in opposite direction could not evoke a response. The current intensity and duration are the same in A. C: Intracellular depolarizing current (intensity: $0.7 \mathrm{nA}$, duration: 100 msec) could not evoke a depolarization. D: Responses to hyperpolarizing current injections with the same intensity and duration as in $\mathrm{C}$. The timing of the illumination is indicated by the elevation of the lower trace attached to each record. The triangles indicate the timings of electrical stimulations. 
tion was the $\mathrm{Ca}^{2+}$ response activated by the depolarizing current at the rod terminal where the $\mathrm{Ca}^{2+}$ channel probably operates in releasing the neurotransmitter. Transretinal current pulses flowing in the opposite direction hardly evoked the response in rods (Fig. 1B). This led Miyachi et al. ${ }^{2}$ to conclude that the current pulse hyperpolarized the rod terminal and could not evoke the $\mathrm{Ca}^{2+}$ response.

However, results of the intracellular current injections were contradictory to their conclusion; when the duration was shortened, the depolarizing current did not evoke the $\mathrm{Ca}^{2+}$ response (Fig. 1C), whereas the hyperpolarizing current injection could evoke it (Fig. 1D). To explain this puzzling phenomenon, further studies were made by means of combination of the intracellular current injections and applications of some ionic channel blockers.

Response of rod to intracellular current injection

1) Effects of polarity and intensity of stimulus current

Fig. 2A shows the rod responses evoked by depolarizing current pulses in normal Ringer solution (Soln $\mathrm{A}$ in Table 1) (upper row) and those by hyperpolarizing pulses (lower row) with increasing intensities, but with a fixed duration. The responses in each row were fundamentally identical in shape irrespective of current intensities. Each response consisted of the rectangular IR drop of the passive membrane resistance and the superimposed active transient components at the onset and termination of the stimulating current. These observations were consistent with those obtained in the 'solitary inner segments' of the salamander. ${ }^{3,4}$ For brevity's sake, the transient components are abbreviated as follows; those evoked at the onset and offset of the depolarizing current as DE-ON and DE-OFF response, and those elicited by the hyperpolarizing current as HYPER-ON and HYPER-OFF response, respectively (Fig. 2A).

Fig. 2B shows current-voltage (I-V) relationships of the responses measured at the peaks of DE-ON and HYPER-ON responses (filled circles) together with those measured just before the termination of the current pulse (filled squares). Both I-V curves showed remarkable outward rectification at the depolarized region, being similar to those measured in 'solitary inner segments' ${ }^{3.4}$ as well as in in situ rods. ${ }^{5,9,10}$ In addition, about $70 \%$ of the cells tested showed inward rectification at the hyperpolarized region though it happened to be not notable in the cell shown in this figure (but see Fig. 5B).

2) Effect of duration and polarity of stimulus current

The effect of stimulus current duration on the response was examined in Soln A (Fig. 3). So far as the duration was reduced down to around $500 \mathrm{msec}$, even the weak current pulses ( $0.3 \mathrm{nA}$ ) could evoke all the transient responses (Fig. 3A and B) and 
Ion channels in frog rod
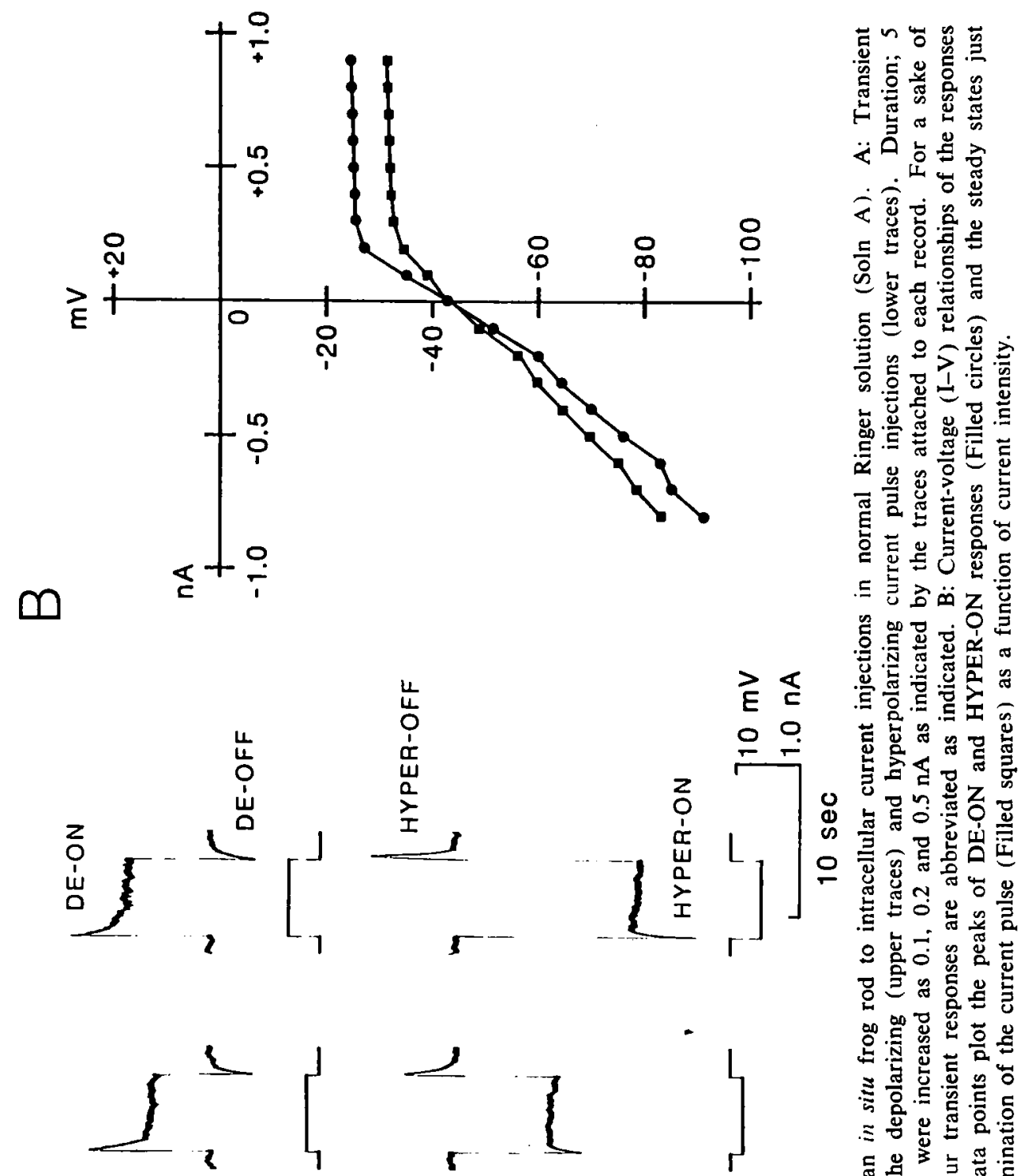

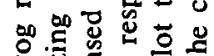

4 준

芌边.

$\Xi \frac{0}{0}$ ㅇ⿺ㅇ

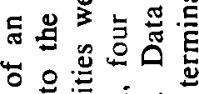

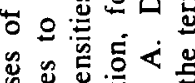

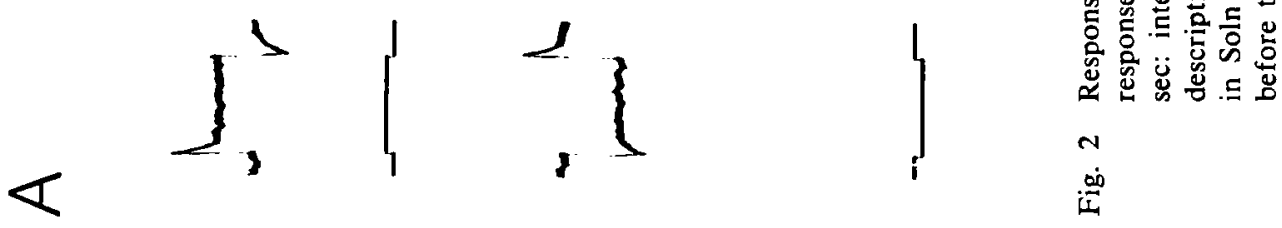


A
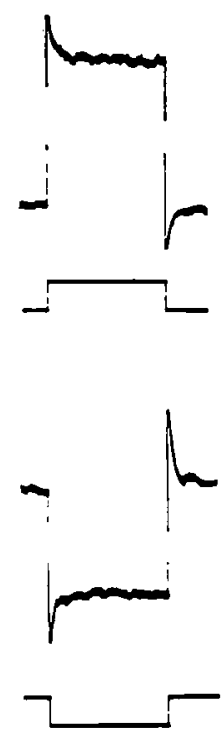

B

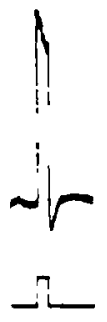

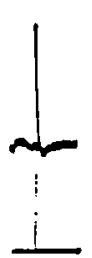
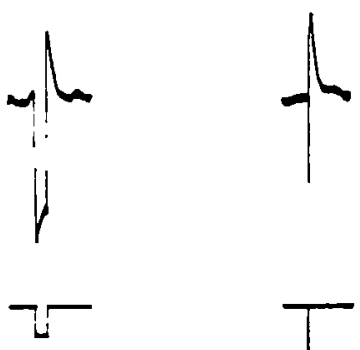

Fig. 3 Responses to intracellular current injections as a function of the duration. The upper and lower rows respectively show responses to the depolarizing and hyperpolarizing current injections in Soln A. The duration of the current pulses was $5 \mathrm{sec}$ in A, $500 \mathrm{msec}$ in $B$, and $5 \mathrm{msec}$ in $C$. The current intensity in $A$ and $B$ was 0.3 $\mathrm{nA}$ for either depolarizing or hyperpolarizing current, and in $\mathrm{C}$ the intensities of the depolarizing and hyperpolarizing current pulses were $2.0 \mathrm{nA}$ and $1.0 \mathrm{nA}$, respectively. The dark membrane potential was $-41 \mathrm{mV}$.

their shapes were fundamentally similar to those shown in Fig. 2. As the duration was shortened further to $5 \mathrm{msec}$, the depolarizing current finally failed to evoke DE-ON response even when the current intensity was increased up to $2 \mathrm{nA}$ (Fig. 3C, upper record), whereas a weaker hyperpolarizing current pulse could still elicit HYPER-OFF response (Fig. 3C, lower record). This finding is contradictory to the previous view that only a depolarizing current can evoke the response, ${ }^{2}$ but it may be understandable in part, if the remarkable outward rectification (Fig. 2B) is taken into account. 


\section{Effect of $\mathrm{Co}^{2+}$ on DE-ON and HYPER-OFF responses}

The experiments on the isolated rods $^{4}$ as well as on in situ rods ${ }^{1,2}$ showed that the cells are capable of producing the $\mathrm{Ca}^{2+}$ response. Its time course was very close to that of DE-ON and HYPER-OFF responses, suggesting that these responses were also attributed to $\mathrm{Ca}^{2+}$ channel activation. To test this possibility, $\mathrm{Co}^{2+}$, a blocker of the voltagedependent $\mathrm{Ca}^{2+}$ channel, was applied to the retina by perfusion (Soln B). In the presence of $3 \mathrm{mM} \mathrm{Co}^{2+}$, the membrane was hyperpo'arized by about $8 \mathrm{mV}$, and HYPEROFF response was considerably suppressed (Fig. 4B). Another effect of $\mathrm{Co}^{2+}$ was an increase of input resistance. Therefore, the stimulating current intensity in either polarity had to be properly reduced to obtain similar amplitudes of IR drops to those in Soln A. However, this does not necessarily mean that the diminution of HYPER-OFF response is due to the reduction of stimulus current intensity. Even with more intense current stimulus, HYPER-OFF response was similarly diminished. Therefore, it is probable that the major component of the response is the voltage-dependent $\mathrm{Ca}^{2+}$ current.

The input resistance increase in $\mathrm{Co}^{2+}$ solution is clearly recognized in the I-V curves (Fig. 4C). The reduced outward rectification in the depolarized region was probably due to a blockade of the $\mathrm{Ca}^{2+}$-dependent $\mathrm{K}^{+}$channel, since the $\mathrm{Ca}^{2+}$ influx was no longer existed. The curves also show the input resistance increase in the hyperpolarized region though the ionic mechanism was unknown.

Even in $\mathrm{Co}^{2+}$ solution, DE-ON, DE-OFF and HYPER-ON responses still survived (Fig. 4B) and their ionic mechanisms will be analyzed in the following sections.

\section{Effect of TEA}

DE-ON response was not eliminated in the $\mathrm{Co}^{2+}$ solution, but was slightly enhanced (compare Fig. 4A and 4B). Therefore, it is doubtful that DE-ON response was attributed solely to $\mathrm{Ca}^{2+}$ channel activation. It is rather possible that the voltage-dependent $\mathrm{K}^{+}$channel was activated by the depolarizing current and it rapidly reduced the passive membrane IR drop which had been increased by the reduced outward rectification (Fig. 4C).

To block the voltage-dependent $\mathrm{K}^{+}$channel, a solution containing tetraethylammonium chloride (TEA) (Soln C) was perfused (Fig. 5). The rod membrane was depolarized by several $\mathrm{mV}$ and the sharp DE-ON response still survived in the TEA solution (Fig. 5B), indicating that the IR drop was reduced not only by the voltagedependent $\mathrm{K}^{+}$channel, but also by probable $\mathrm{Ca}^{2+}$-dependent $\mathrm{K}^{+}$channel activation (see the next section).

The other prominent effect of TEA was to increase the input resistance, and accordingly the same intensity of stimulating current produced a greater amplitude of the response than that in control solution (Fig. $5 \mathrm{C}$ ). In addition, the normally negative 


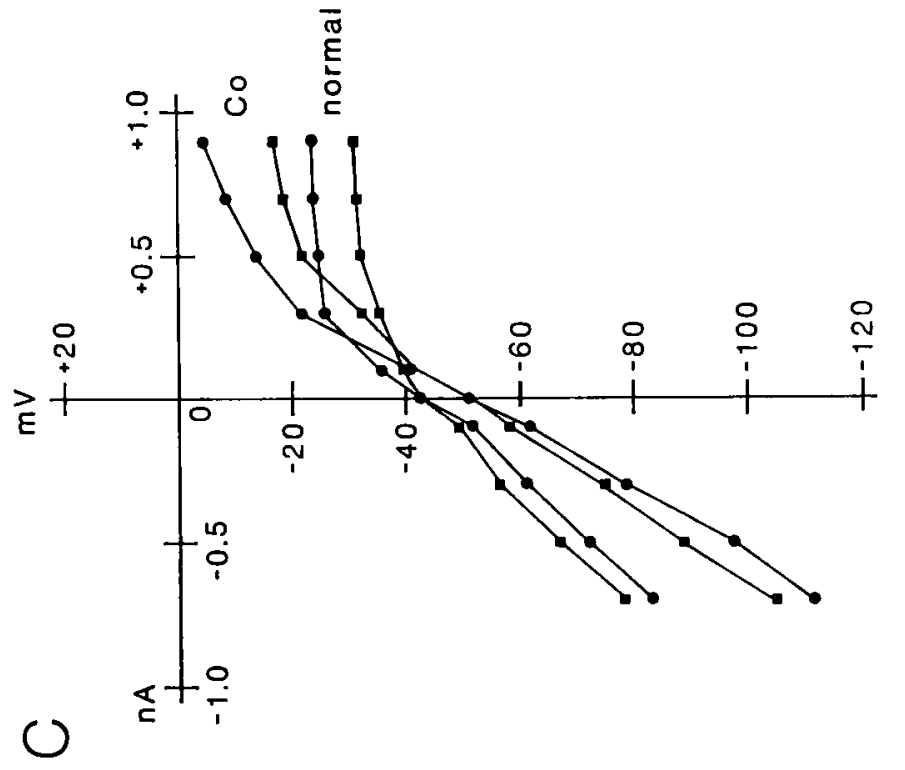

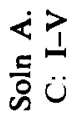

$\Xi \dot{4}$

迷

奇.

氖急哭

象计

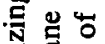

氙

음 통

g

茟

渮

焉怘

․․ㄹ

政

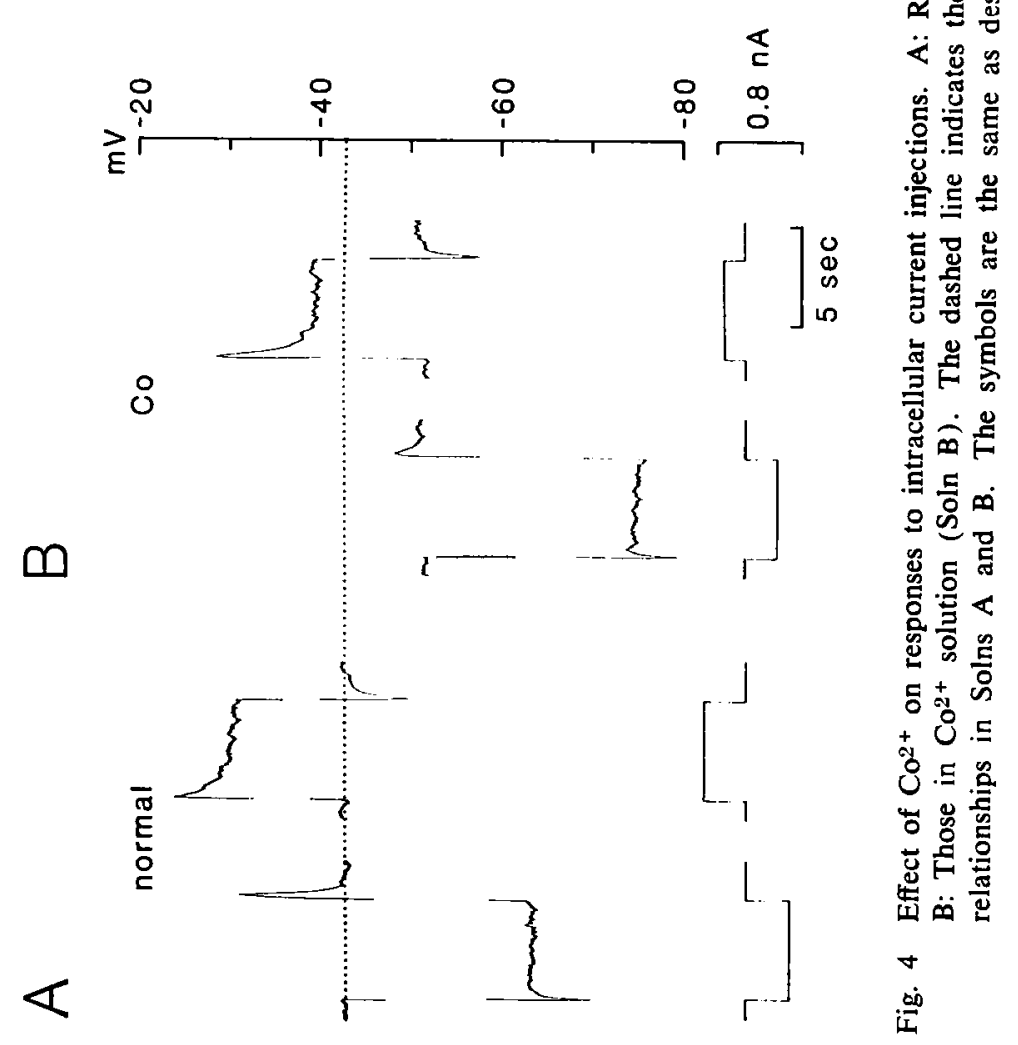




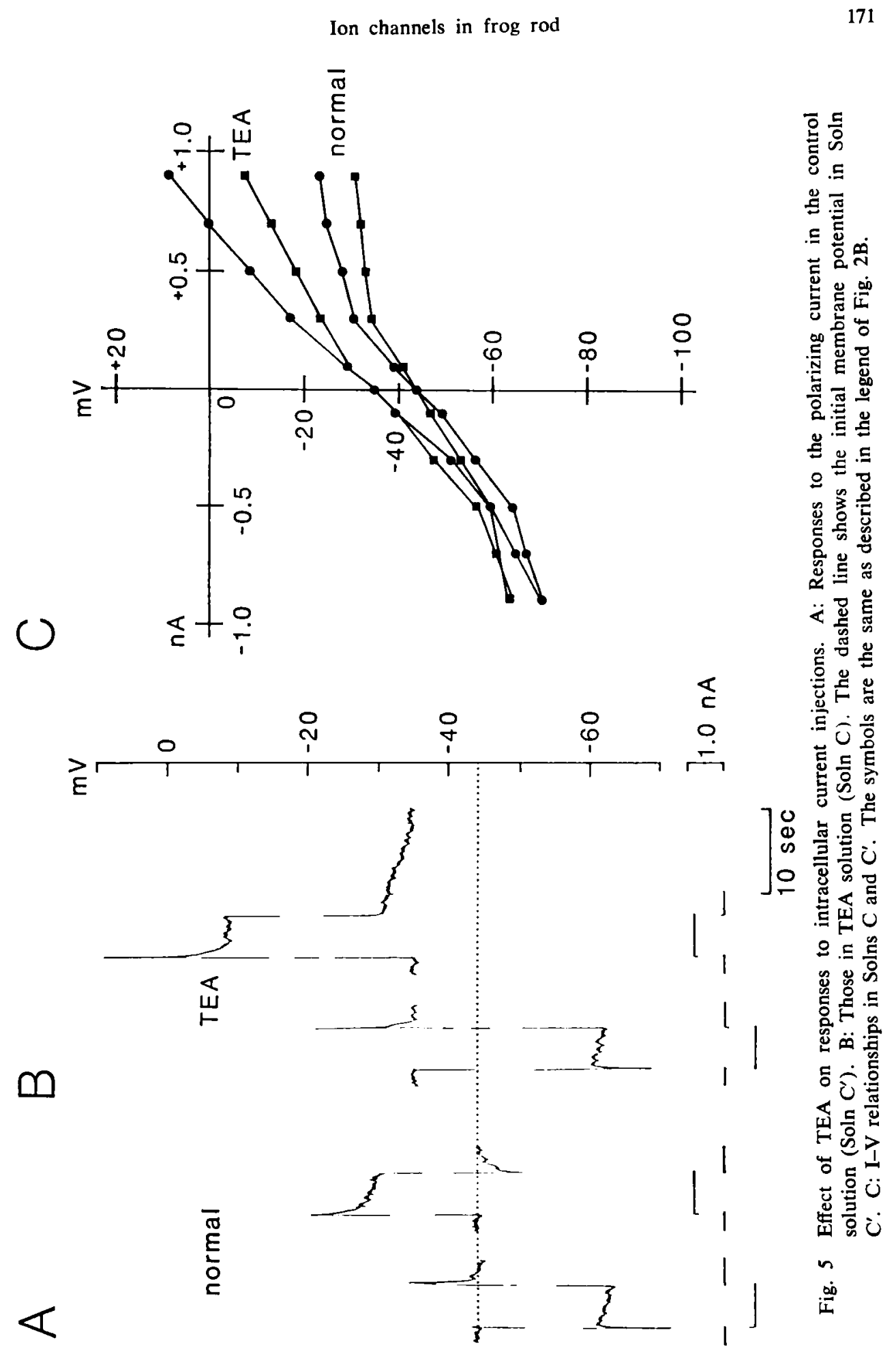


DE-OFF response (Fig. 5A) turned to a long-lasting positive after-depolarization (Fig. 5B). It was therefore suggested that the negative DE-OFF response was attributable to the tail of the vo'tage-dependent $\mathrm{K}^{+}$current. In fact, when the $\mathrm{K}^{+}$channel was blocked by TEA, the vo'tage-dependent $\mathrm{Ca}^{2-}$ current became apparent to form the after-depolarization. These observations were consistent with those by other investigators. ${ }^{5}$

In TEA solution (Soln $\mathrm{C}$ ), the concentration of $\mathrm{Na}^{+}$was reduced by $20 \mathrm{mM}$. Therefore, the effect described above might be due to low $\mathrm{Na}^{+}$concentration. In Soln $\mathrm{C}^{\prime}$ ( $20 \mathrm{mM}$ TEA was replaced by $20 \mathrm{mM}$ choline), however, no appreciable effect was observed (not shown), confirming that the effect was solely attributed to TEA.

Effect of simultaneous application of TEA and $\mathrm{Co}^{2+}$

When TEA alone was applied (Fig. 6A), the effect was, of course, the same as has been described in Fig. 5. When TEA and $\mathrm{Co}^{2+}$ were simultaneously applied (Soln D), the response to the depolarizing current turned into almost rectangular shape, and there seemed no indications of activation of both $\mathrm{Ca}^{2+}$ and $\mathrm{K}^{+}$channels (Fig. 6B). Therefore, it is quite likely that the rectangular response is only the IR drop of the

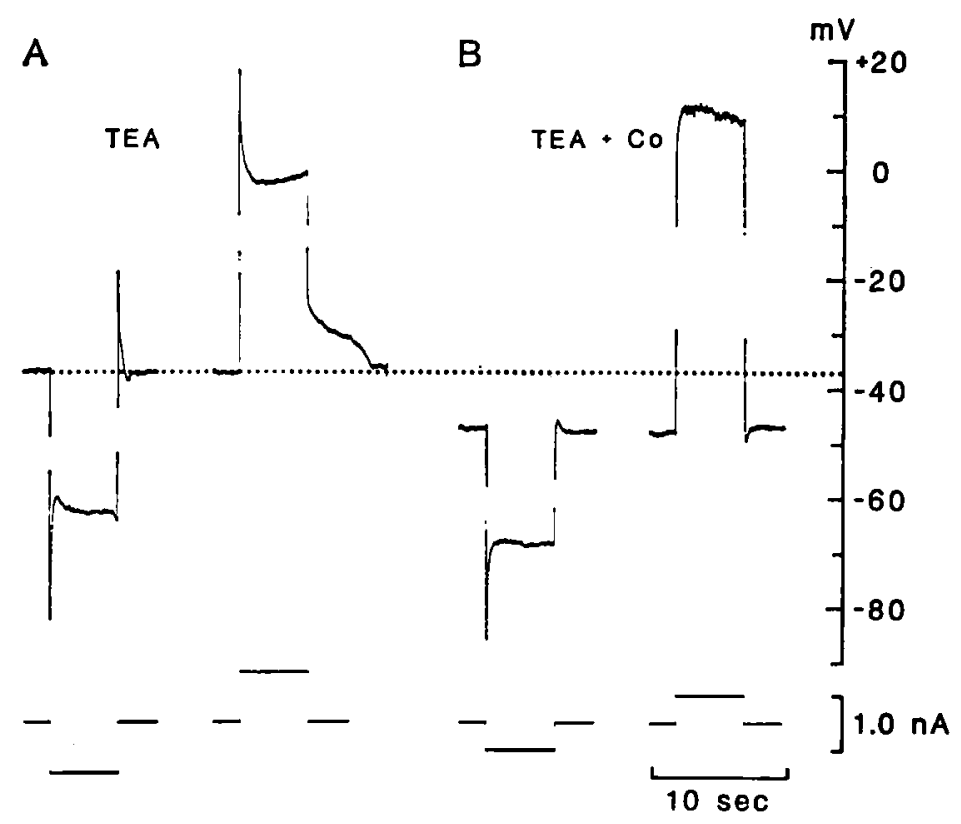

Fig. 6 Effect of simultaneous application of TEA and $\mathrm{Co}^{2+}($ Soln D) on responses to intracellular current injections. A: Responses observed in TEA solution (Soln C). B: Responses observed in Soln D which contained both TEA and $\mathrm{Co}^{2+}$. The dotted line indicates the dark membrane potential in Soln C. 
passive membrane resistance. In addition, HYPER-OFF response was greatly suppressed. It now becomes clear that the rod membrane contains $\mathrm{Ca}^{2+}$ and $\mathrm{K}^{+}$channels which are both voltage-dependent, and that they interacted to form a transient DE-ON response. Even in Soln E, HYPER-ON response still survived, so that its ionic mechanism will be analyzed in the next section.

\section{Effects of $\mathrm{Cs}^{+}$}

In Soln A, the hyperpolarizing current produced HYPER-ON and HYPER-OFF responses (Fig. 7A a). When the membrane potential was hyperpolarized by illumination, HYPER-ON response was enhanced whereas HYPER-OFF response was slightly reduced (Fig. 7A b). The blockers so far used, $\mathrm{Co}^{2+}$ and TEA, could not eliminate HYPER-ON response, suggesting that this negative transient response is attributed to some other ionic current which is activated by the hyperpolarizing current, and the $\mathrm{h}$ current is most likely. In fact, application of $\mathrm{Cs}^{+}$, the h current blocker (Soln E), almost completely suppressed HYPER-ON response as shown in Fig. 7A c. In addition, $\mathrm{Cs}^{+}$eliminated the inward rectification at the hyperpolarized level, leaving the outward rectification at the depolarized level almost as it was (Fig. 7B). In $\mathrm{Cs}^{+}$solution (Soln E) the concentration of $\mathrm{Na}^{+}$was reduced by $10 \mathrm{mM}$, and this might be a cause of the above effect. However, the control experiment in Soln $\mathrm{E}^{\prime}\left(10 \mathrm{mM} \mathrm{Cs}^{+}\right.$was replaced by $10 \mathrm{mM}$ choline) showed no such effect, indicating the effect was solely attributed to $\mathrm{Cs}^{+}$. This suggests that HYPER-ON response is attributed to the $h$ current. ${ }^{4,6, i}$

The amplitude of HYPER-OFF response was slightly reduced when the membrane potential was hyperpolarized by illumination, while in $\mathrm{Cs}^{+}$solution the large HYPEROFF response was still produced when the stimulating current was adjusted to produce a similar amplitude of the response (Fig. $7 \mathrm{Ac}$ ). When the membrane potential was hyperpolarized by illumination, the response was much reduced (compare Fig. 7A b with $7 \mathrm{Ad}$ ). This indicates that the response is attributed in part to the anode break excitation of the $\mathrm{Ca}^{2+}$ channel as well as to the tail of the $\mathrm{h}$ current in another part. In order to confirm the above view, it should be necessary to apply $\mathrm{Co}^{2+}$ and $\mathrm{Cs}^{+}$ simultaneously. However, the membrane potential became extraordinarily unstable in the solution and reliable results were not obtained.

Effects of ion channel blockers on the membrane potential and light response

As described above, the ion channels are common in the in situ rod and the isolated rod irrespective of animal species. In order to understand the physiological roles of these ion channels, effects of ion channel blockers were observed on the rod membrane potential as well as on the light response. This experiment may be impossible to perform in the isolated rods, since their outer segments are usually lost during the dissociation procedures and accordingly no light response can be induced. 


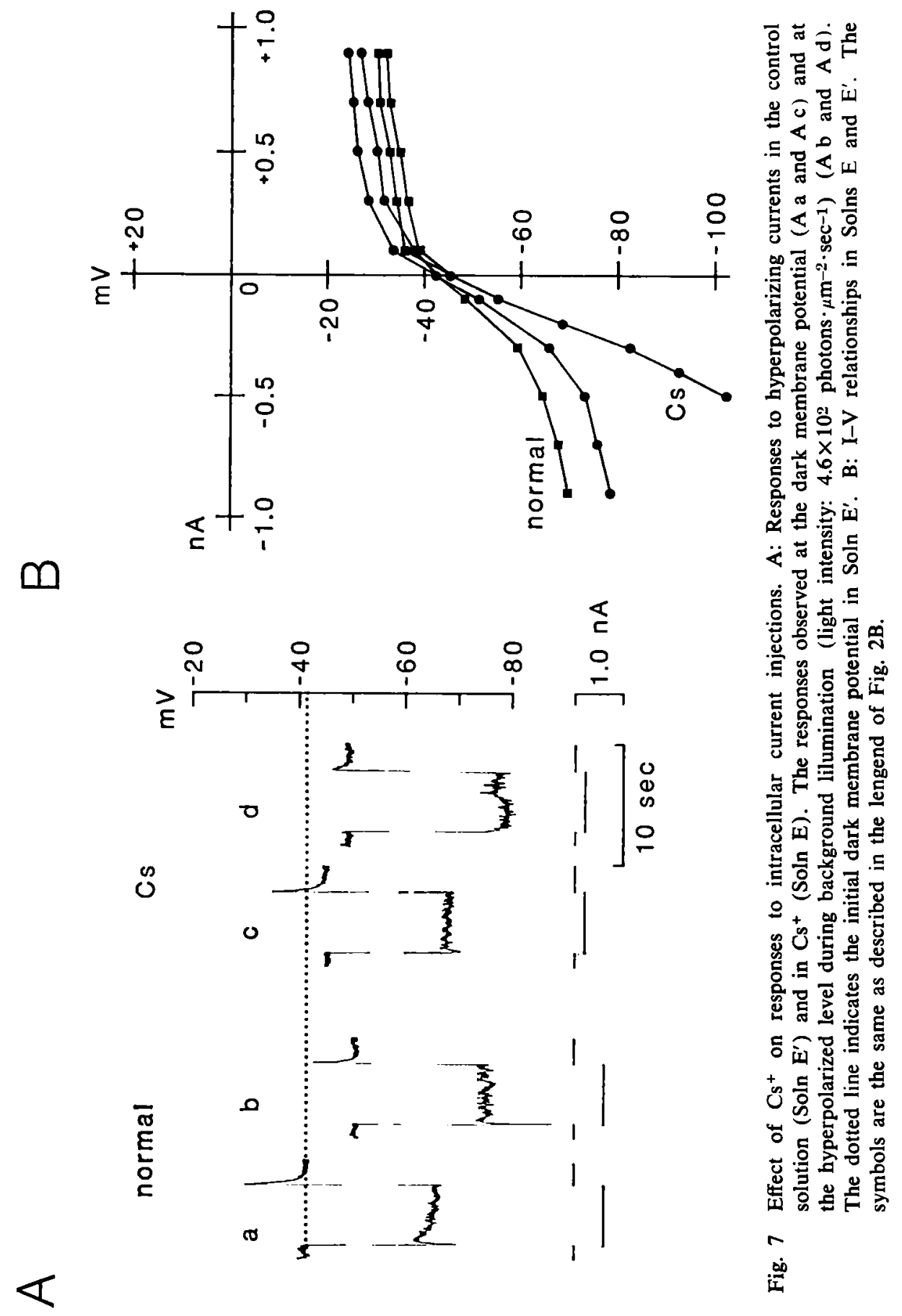



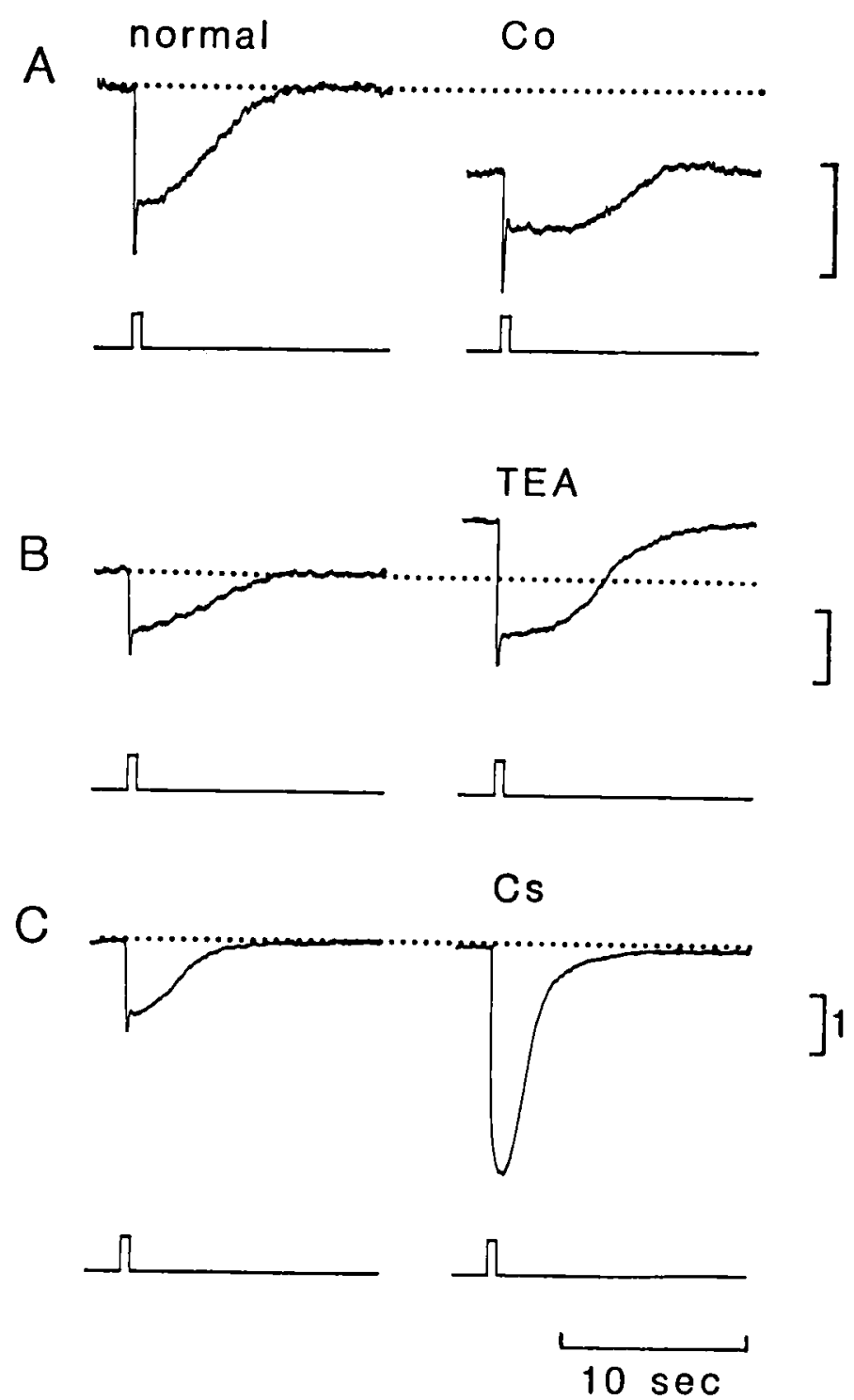

Fig. 8 Effects on the dark membrane potential and light response of ion channel blockers; $\mathrm{Co}^{2+}(\mathrm{A})$, TEA (B) and $\mathrm{Cs}^{+}(\mathrm{C})$. The lower trace attached to each record indicates the timing of the light stimulation. The dotted lines indicate the initial dark membrane potentials in respective control solutions; $-41 \mathrm{mV}$ in $\mathrm{A},-43 \mathrm{mV}$ in $\mathrm{B}$, and $-40 \mathrm{mV}$ in $\mathrm{C}$. 
In Soln $A$, the rod membrane potential in the dark (the dark level) was usually around $-40 \mathrm{mV}$, and the response to a light flash consisted of an initial negative sag and a subsequent tail (Fig. 8A, normal). When $\mathrm{Co}^{2+}$ was perfused, the dark level shifted to hyperpolarizatoin, but the sustained level of the light response after the sag remained at the almost same level as that in the normal solution, thus resulting in a decrease of the light response amplitude (Fig. 8A, Co). The results indicated that $\mathrm{Ca}^{2+}$ channel was continuously active in the dark. Therefore, it is probable that the rod is depolarized in the dark by both ionic influxes, that is, $\mathrm{Na}^{+}$influx through the outer segment membrane and $\mathrm{Ca}^{2+}$ influx through the inner segment membrane. ${ }^{1,4,5}$

Application of TEA frequently resulted in generation of a damped oscillation on the tail of the light response, ${ }^{1}$ and the oscillation disturbed the measurement of the accurate membrane potential level. Therefore, the experiment was carried out on a cell which has no oscillation (Fig. 8B). By TEA application, the dark level was shifted towards depolarization, and the light response amplitude became larger (Fig. 8B, TEA). The depolarizing shift of the dark level is possibly due to the blockade of the voltagedependent $\mathrm{K}^{+}$channel which normally holds the dark level at the hyperpolarized level. In addition, the experiment indicated the additional contribution of $\mathrm{Ca}^{2+}$ channel as well. After the effect of TEA was observed, the solution which contained both TEA and $\mathrm{Co}^{2+}$ (Soln D) was perfused. The dark level was shifted towards hyperpolarization (cf. Fig. 6) and the light response was greatly diminished (not shown). Therefore, it might be possible that the depolarization caused by TEA further activated the $\mathrm{Ca}^{2+}$ influx, thus resulting in a large depolarizing shift of the dark level.

$\mathrm{Cs}^{+}$did not affect the dark level, whereas considerably enhanced the light response (Fig. 8C). This is consistent with the other reports that the initial sag is due to the activation of the $h$ current. ${ }^{3-5,7}$

The above observations indicate that the $\mathrm{Ca}^{2+}, \mathrm{K}^{+}$and $\mathrm{h}$ currents contribute to stabilize the membrane potential of the rod at an appropriate range where the light responses are efficiently produced (see Discussion).

\section{Discussion}

Ion channels in rods in situ

The ion channels have been precisely analyzed in enzymatically isolated rods. However, it is still anxious whether the channels in isolated cells can retain their characteristics being resistant to the dissociation procedures. The present experiment indicates that the ion channels found in the isolated cells are commonly observed in in situ rods as summarized below (Fig. 9). DE-ON response was not abolished by separate application of either $\mathrm{Co}^{9+}$ or TEA (Figs. 4 and 5), but was completely eliminated by simultaneous application of both blockers (Fig. 6). Therefore, it is suggested that 


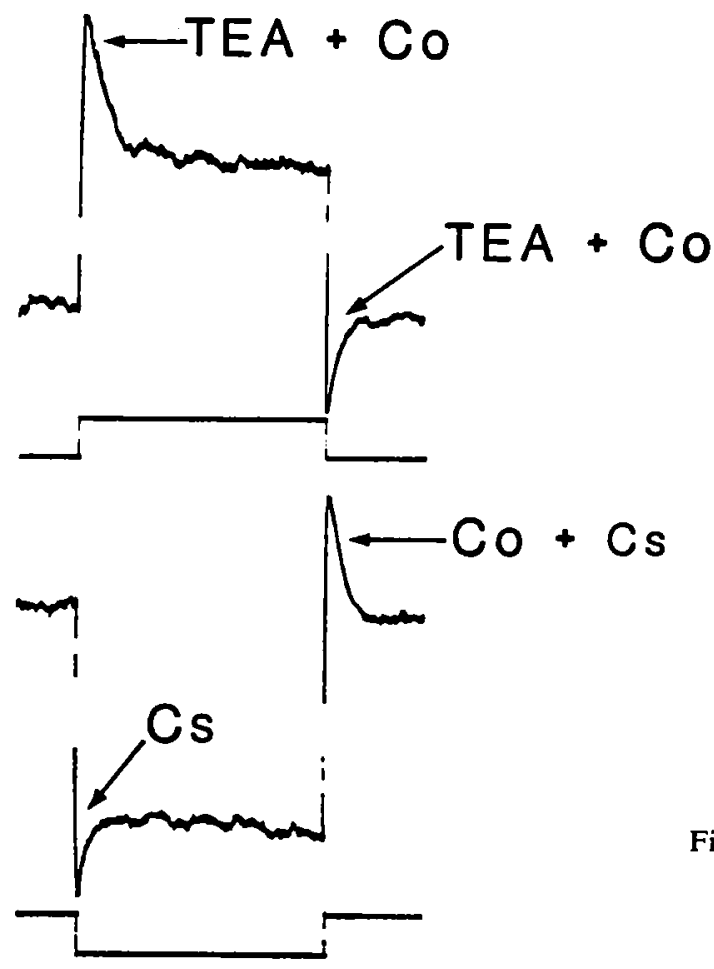

Fig. 9 A scheme summarizing the effects of the ion channel blockers on responses in frog rods in situ.

DE-ON response consists of two transient components; one is the voltage-dependent $\mathrm{Ca}^{2+}$ current which is susceptible to $\mathrm{Co}^{2+}$, and the other is the voltage-dependent $\mathrm{K}^{+}$ current which is sensitive to TEA. The latter is activated by depolarization and counteracts with the depolarization to reduce its amplitude in a time-dependent manner, thus forming a transient response. In isolated rods, another $\mathrm{K}^{+}$current has been known to be activated by $\mathrm{Ca}^{2+}$ influx $\left(\mathrm{Ca}^{3+}\right.$-dependent $\mathrm{K}^{+}$current $)$. Therefore, contribution of this $\mathrm{K}^{+}$current to $\mathrm{DE}-\mathrm{ON}$ response cannot be excluded.

When TEA was applied, the negative DE-OFF response turned to the positive afterdepolarization (Figs. 5B and 6A) which was completely eliminated by simultaneous application of TEA and $\mathrm{Co}^{2+}$ (Fig. 6B), suggesting that DE-OFF response consists of the voltage-dependent $\mathrm{Ca}^{2+}$ current and the tail of the voltage-dependent $\mathrm{K}^{+}$current. ${ }^{5}$

HYPER-ON response was abolished by $\mathrm{Cs}^{+}$(Fig. 7), indicating the contribution of the $\mathrm{h}$ current or $\mathrm{K}^{+}$current flowing through anoma'ous rectifier. The present experiment could not distinguish them from each other, but other investigators have suggested that the former is likely. ${ }^{4}$

HYPER-OFF response was suppressed by $\mathrm{Co}^{2+}$ (Fig. 4), suggesting that the re- 
sponse is mainly attributed to the $\mathrm{Ca}^{2+}$ channel activated by anode break excitation. In addition, the tail of the $\mathrm{h}$ current may also participate in part, since $\mathrm{Cs}^{+}$reduced HYPER-OFF response (Fig. 7A).

Rod response evoked by transretinal current pulse

In the frog rods perfused with the normal Ringer solution, the $\mathrm{Ca}^{2+}$ response was produced when the retina was stimulated by externally applied transretinal current flowing from the receptor side to the vitreous side. ${ }^{2}$ Considering the current direction, it is likely that HYPER-OFF response occurs somewhere in the distal region where the current enters inside the rod and DE-ON response is evoked at the proximal region from where the current leaves. Therefore, the $\mathrm{Ca}^{2+}$ response evoked by the transretinal current may be combination of DE-ON and HYPER-OFF responses. However, the intracellular current injection failed to evoke DE-ON response when the duration was reduced to the same $5 \mathrm{msec}$ as used in the transretinal current stimulation (Fig. 3). Therefore, the $\mathrm{Ca}^{2+}$ response evoked by the transretinal current was mainly attributed to HYPER-OFF response. However, the contribution of DE-ON response could not be excluded, since the current intensity flowing inside the rod was unknown. No matter how and where the $\mathrm{Ca}^{2+}$ responses may occur, these can be intracellularly recorded as a spatially summative response.

Physiological role of ion channels: membrane potential stabilization

In the dark, membrane potentials of rods and cones are fairly stable at the potential levels which are not the equilibrium potentials of such common ions as $\mathrm{Na}^{+}, \mathrm{K}^{+}$, or $\mathrm{Cl}^{-}$. In the cone system, it was suggested that the feedback loop is present between the cones and the horizontal cells, and that the feedback partly contributes to stabilization of the membrane potential in both cells. ${ }^{11,12}$ However, the study by Miyachi et al. ${ }^{2}$ as well as the other reports ${ }^{1,13,14}$ have indicated that there is no such feedback loop in the rod system. Therefore, the membrane potential stability is difficult to explain, if only the $\mathrm{Na}^{+}$influx through the outer segment membrane is considered. The experiment shown in Fig. 8 gives some clue to understand the mechanism. It is probably the case that such ion channels in the inner segment as the voltage-dependent $\mathrm{Ca}^{2+}, \mathrm{K}^{+}$and $\mathrm{h}$ currents operate in the normal range of the membrane potential..$^{4 . \bar{\nu}}$ If so, any membrane potential fluctuation may be counteracted by the opposing ion channel activation. For example, if the membrane potential fluctuates towards a more depolarized level, the $\mathrm{K}^{+}$ channel is more activated to hyperpolarize the membrane. On the other hand, the membrane shifts to hyperpolarization, the $h$ current is activated to counteract. These mechanisms actually operate even in the isolated inner segments and the membrane potential is fairly stabilized. ${ }^{4}$ 


\section{Acknowledgements}

This work was supported by the Research-Aid Fund from Keio University School of Medicine. The author is grateful to Prof. M. Murakami for his helpful comments and critical reviewing of this manuscript.

\section{References}

1. Fain, G. L., Gerschenfeld, H. M. and Quandt, F. N.: Calcium spikes in toad rods. J. Physiol. (Lond.) 303: 495-513, 1980

2. Miyachi, E.-I., Takahashi, K.-I. and Murakami, M.: Electrically evoked calcium responses in rods of the frog retina. Jpn. J. Physiol. 34: 307-318, 1984

3. Bader, C. R., MacLeish, P. R. and Schwartz, E. A.: Responses to light of solitary rod photoreceptors isolated from tiger salamander retina. Proc. Natl. Acad. Sci. USA 75: 3507-3511, 1978

4. Bader, C. R., Bertrand, D. and Schwartz, E. A.: Voltage-activated and calcium-activated currents studied in solitary rod inner segments from the salamander retina. J. Physiol. (Lond.) 331: 253-284, 1982

5. Fain, G. L. and Quandt, F. N.: The effects of tetraethylammonium and cobalt ions on responses to extrinsic current in toad rods. J. Physiol. (Lond.) 303: 515-533, 1980

6. Fain, G. L., Quandt, F. N., Bastian, B. L. and Gerschenfeld, H. M.: Contribution of a caesium-sensitive conductance increase to the rod photoresponse. Nature 272: 467-469, 1978

7. Werblin, F. S.: Time- and voltage-dependent ionic components of the rod response. J. Physiol. (Lond.) 294: 613-626, 1979

8. Normann, R. A. and Pochobradsky, J.: Oscillations in rod and horizontal cell membrane potential: Evidence for feed-back to rods in the vertebrate retina. J. Physiol. (Lond.) 261: $15-29,1976$

9. Lasansky, A. and Marchiafava, P. L.: Light-induced resistance changes in retinal rods and cones of the tiger salamander. J. Physiol. (Lond.) 236: 171-191, 1974

10. Werblin, F. S.: Regenerative hyperpolarization in rods. J. Physiol. (Lond.) 244: 53-81, 1975

11. Murakami, M., Shimoda, Y., Nakatani, K., Miyachi, E.-I. and Watanabe, S.-I.: GABAmediated negative feedback from horizontal cells to cones in carp retina. Jpn. J. Physiol. 32: $911-926,1982$

12. Murakami, M., Shimoda, Y., Nakatani, K., Miyachi, E.-I. and Watanabe, S.-I.: GABAmediated negative feedback and color opponency in carp retina. Jpn. J. Physiol. 32: 927935,1982

13. Brown, J. E. and Pinto, L. H.: Ionic mechanism for the photoreceptor potential of the retina of Bufo marinus. J. Physiol. (Lond.) 236: 575-591, 1974

14. Copenhagen, D. R. and Owen, W. G.: Coupling between rod photoreceptors in a vertebrate retina. Nature 260: 57-59, 1976 